\title{
The use of the city in space and time as a new social approach for prioritising transport corridors in the metropolitan area of Barcelona (Spain)
}

\author{
J. Cerda \& C. Marmolejo \\ Centro de Política de Suelo y Valoraciones, \\ Universidad Politécnica de Cataluña, Spain
}

\begin{abstract}
The traditional evaluation of transport projects principally considers the benefits produced by the reduction in journey time of the travellers, but a specific reduction is not the same for a one-hour trip as for one of 20 minutes, or for a work-related journey as for a shopping-related journey. The purpose of this investigation is to construct a Pattern of Social Behaviour in the use of the city (in space and time), and specifically the travel time patterns, to use them to prioritise different transport corridors, in the Metropolitan Area of Barcelona, under a social equity approach, in journey time. The study applies a trip chain analysis (similar to activity-based models) over the travel survey of the metropolitan area of Barcelona (2001). The results are analysed in a probabilistic dimension of Hagerstrand's time-geography approach. The result is a new indicator of access, called functional probability, which derives from how people move in the city. This "willingness to spend time on travel" was used to identify outliers travel time, as a social equity factor, in the use of the city. The threshold of $10 \%$ of the greater travel time was used to identify inequitable travel (with different purposes and social class of travellers). Finally, the assignment of these inequity trips shows transport corridors with different spatial specialisation. The main conclusion of the research is that taking a social view of travellers, with regard to their different purposes and social class, in the form of how they use the city in terms of space and time, is a more realistic criterion to prioritise different transport corridors, by carrying out the analysis of who makes use of them, for what reason, and for how long.
\end{abstract}

Keywords: social use of the city, prioritising transport corridors. 


\section{Introduction}

The traditional evaluation of transport projects is included principally in a strategic transport study. The object of these studies is the identification and evaluation of a group of transport projects, named a project plan, for the existing city and the city of the future. These types of studies apply the traditional fourstage transportation model [6]. The first stage evaluates the generation and attraction of trips in each transportation zone of the city. The second stage predicts the spatial distribution of these trips, followed by the modal distribution. Finally, the model assigns the trips to a multi modal transportation network. In this last stage, the model can include a specific transport project as a modification of the transport network.

The evaluation of transport projects principally considers the benefit produced by the reduction in travel time of vehicles and passengers, in the new transport network. The reduction of travel time is multiplied by a constant value named "social value of time" to obtain economic benefit [2].

Today many studies consider others factors, named externalities, in the evaluation process. The most popular types of externalities are environmental externalities, such as gas emissions and noise pollution. Other externalities are the security condition of the transport network [1].

The above methodology, classical in transportation studies, arises from the causal paradigm of understanding the relationship between transport and city. This paradigm has been widely criticised by social scientists as being very functional, because it reduces the human dimension (and urban dimension) to a simple trip [9].

The social background of the "value of time" is only conceptual, based on the assumption that society as a whole assigns a value to the reduction of travelling time, or by the economic value of the time productivity ratio from a worker [10].

The question here is how to include the urban and human dimension in the transportation model, and also in the evaluation process of transport projects. The research problem of this study is that a specific travel time reduction does not have the same effect in a one-hour trip as in one of 20 minutes, or for a work related trip as for a shopping trip.

The purpose of the investigation is to construct a Pattern of Social Behaviour in the use of the city (in space and time), and specifically the travel time pattern, to use them to prioritise (under a social equity approach, in travel time) different transport corridors, in the Metropolitan Area of Barcelona.

The document is divided into four sections. The first section introduces an approach for quantifying the use of the city in time and space. The second section presents the methodology. The third section presents the results obtained for the Metropolitan Area of Barcelona, and finally the main conclusions are presented.

\section{The use of the city in space and time}

Hagerstrand (1969) built a powerful conceptual and analytical basis for the understanding of urban social phenomenon, named "time geography" [8]. Time 
geography highlights the necessary condition for participating in activities distributed sparsely with respect to space, and is available for only limited temporal durations. This theory identified the spatial and temporal constraints under which individuals participate in activity episodes using the now wellknown space-time prism (authority constrains). It also identifies capability constraints (biological restrictions, income, car availability, etc.), and coupling constraints (conditions to meet with other persons). All these conditions address the question of how participating in activity at a given place and time affects abilities to participate in activities in other places and at other times $[3,8]$.

This individual approach has been widely applied in urban sociology, specifically on issues of human perception, contacts between social classes, living space, and the new concept of "Motility" [7].

Moreover, activity theory examines how aggregate human phenomena emerge from individual activity participation in space and time, as well as the mode and route choice when moving between these activities. This approach started gaining attention in 1980s. Only in 1990s did the travel demand analysis accelerate the shift to the new activity-based paradigm [4].

Time geography and activity theory are long-standing intellectual traditions, in geography and transportation science, respectively. However, the aggregate analysis of people (not individuals) in these approaches is unusual. The "transport" vision of the city is socially reductionist, because its separation of transport from the associated activities is a mistake.

The understanding of how people use the city is directly related to the behaviour of their users. People, with their characteristics and decisions are those that use the city. The behaviour of a type of resident should be investigated, in the interactions and periods spent inside the city, for specific purposes. This behaviour arises from a probabilistic analysis of the usage of the city, which is built based on the behaviour of many residents (and not an individual approach) [5].

This research understands the use of the city as the form how people, in a mass approach, satisfy their needs in the activities inside the city. This satisfaction of needs has two analytical dimensions, and two actions. The dimensions are time and space, and the actions are access and remaining therein, both in specific activities in the city.

The combination of both dimensions and actions creates the "time to access" and "time to stay", "space to access" and "space to stay", for/in a specific activity. The pattern of access time, and staying time, represent the associated probability distribution.

The present work is part of a larger project that examines these two dimensions and actions in different cities. This paper shows the results of the combination of the travel time pattern, together with the pattern of use of transport network (space), for different purposes (activities).

The newness of this approach are 1) the capacity to differentiate the flow (not in the mode of transportation) for different purposes (activities), and 2) the possibility to determine travel time thresholds, for purpose, to identify situations of social inequality. 


\section{Methodology}

The study applies a trip chain analysis (similar to the activity-based transportation model) over the travel survey of the metropolitan area of Barcelona (2001). This analysis allows the validation of the travel database, in order to identify time and spatial codification mistakes.

With the final database, the probability distribution of travel times is constructed for different purposes (to work, to study, to shop, for leisure, for social reasons). The inverse cumulative distribution of travel time for each purpose is used as a new indicator of temporal access, named "functional probability". The functional probability, as a "willingness to spend time on travel", was used to identify outliers' travel times, as a social equity criterion in the use of the city.

Different distribution matrices were constructed with the inequitable trips, and also with the total trips for each purpose. These matrices were assigned to the structural network of the Metropolitan Area of Barcelona. The assignment method was an "all or nothing" optimisation, because the objective is to prioritise structural corridors at the metropolitan scale.

The product from the assignment model was different flows of the inequitable trips, and total trips, for each purpose, for each arc of the network. Finally, a specialisation index was calculated of inequity trips to prioritising transport corridors with different purposes.

\section{Results}

The original database has 17,310,838 trips (per week), the destinations of which are activities (excluding the return to home trip). The trip chain analysis identifies 2,795,566 trips with different mistakes $(16 \%)$. The final database has $14,515,272$ trips (per week). Table 1 shows the functional probability obtained for travel times.

Table 1 shows that a reduction of five minutes of travel time does not produce the same effects for a one-hour trip as for one of 20 minutes, or for a working trip as for a shopping trip. The functional probability, as the probability to make the trip, varies differentially. The reduction of 5 minutes in a one hour trip (from 60 to 55 minutes), varies the probability from 0.076 to 0.077 . The same reduction in a trip of 25 minutes (from 25 to 20 minutes), varies the probability from 0.414 to 0.744 . In the first situation, the trip goes from a very low probability to practically the same. In the second situation, the trip goes from a middle probability to a high probability.

In another way, the reduction of 5 minutes in a trip of 20 minutes (from 20 to 15 minutes), increases the probability to 0.16 if the purpose is to work, but the increase is 0.29 if the purpose is to shop.

So, the functional probability shows a "willingness to spend time on travel", in other words it is the probability to make or not the trip, with a specific purpose. Then the variation of probability produced by a reduction of time is not constant like as the social value of time. 
Table 1: Functional probability of travel time for different purposes, Barcelona (2001).

\begin{tabular}{|c|c|c|c|c|c|c|}
\cline { 2 - 7 } \multicolumn{1}{c|}{} & \multicolumn{5}{|c|}{ Purpose } & \\
\hline Travel time (min) & To work & To study & To shop & Leisure & Social & Total \\
\hline $0-5$ & 100,0 & 100,0 & 100,0 & 100,0 & 100,0 & 100,0 \\
\hline $5-10$ & 96,4 & 95,0 & 94,4 & 94,7 & 95,7 & 95,9 \\
\hline $10-15$ & 94,6 & 91,9 & 91,1 & 92,2 & 93,2 & 93,5 \\
\hline $15-20$ & 79,1 & 69,0 & 62,4 & 74,7 & 70,0 & 74,4 \\
\hline $20-25$ & 48,4 & 32,1 & 28,7 & 38,7 & 36,3 & 41,4 \\
\hline $25-30$ & 47,5 & 31,3 & 27,9 & 37,9 & 35,3 & 40,5 \\
\hline $30-35$ & 44,5 & 29,0 & 25,8 & 35,3 & 32,3 & 37,7 \\
\hline $35-40$ & 17,8 & 13,0 & 8,3 & 13,7 & 11,7 & 15,5 \\
\hline $40-45$ & 17,3 & 12,5 & 8,1 & 13,4 & 11,4 & 15,1 \\
\hline $45-50$ & 14,2 & 10,7 & 7,1 & 11,6 & 9,7 & 12,7 \\
\hline $50-55$ & 8,3 & 6,9 & 4,6 & 5,9 & 5,2 & 7,7 \\
\hline $55-60$ & 8,2 & 6,8 & 4,6 & 5,8 & 5,1 & 7,6 \\
\hline $60-65$ & 7,9 & 6,5 & 4,4 & 5,7 & 4,9 & 7,4 \\
\hline $65-70$ & 2,1 & 2,4 & 1,8 & 1,8 & 1,8 & 2,5 \\
\hline $70-75$ & 2,0 & 2,3 & 1,7 & 1,8 & 1,8 & 2,5 \\
\hline $75-80$ & 1,8 & 2,1 & 1,5 & 1,6 & 1,6 & 2,3 \\
\hline $80-85$ & 1,2 & 1,4 & 1,3 & 1,1 & 1,0 & 1,6 \\
\hline $85-90$ & 1,2 & 1,4 & 1,3 & 1,1 & 1,0 & 1,6 \\
\hline & & & & & & \\
\hline
\end{tabular}

Table 2: $\quad$ Equity-inequity threshold for different purposes.

\begin{tabular}{|c|c|c|c|c|c|c|}
\cline { 2 - 7 } \multicolumn{1}{c|}{} & \multicolumn{5}{|c|}{ Purpose threshold (min) } & \multirow{2}{*}{} \\
\hline Percentile & To work & To study & To shop & Leisure & Social & Total \\
\hline 50 & 19,7 & 17,6 & 16,8 & 18,4 & 18,0 & 18,7 \\
\hline 75 & 33,6 & 31,2 & 30,2 & 32,4 & 31,8 & 32,9 \\
\hline 90 & 48,6 & 46,0 & 34,5 & 46,4 & 44,0 & 47,7 \\
\hline 95 & 62,5 & 61,9 & 49,2 & 60,9 & 58,2 & 62,5 \\
\hline 99 & 69,9 & 75,7 & 64,6 & 64,7 & 64,7 & 77,0 \\
\hline
\end{tabular}

Understanding this functional probability as a social cost of travel allows for the identification of equity or inequity situations in travel times. However, to identify an equity situation, a specific threshold must be defined. There are two main ways of determining the time threshold of equity-inequity; the first is to determine the threshold based on a maximum acceptable condition for a traveller (absolute magnitude of the threshold), which may be a product of specific social policy. The second way is to make the threshold relative to the situation of all travellers (statistical criterion).

This study uses the second way to identify the equity-inequity threshold. Table 2 shows the threshold values (in minutes) for different criteria (percentiles) over the functional probability distributions. 
As expected, for each statistical criterion, the time thresholds vary according to the purpose of the trip, and also with respect to total travel. This shows the error to consider only the situation of total trips to define a threshold. For example, with the threshold of 47.7 minutes (total trips), we identify $10 \%$ of longer trips in time. However, this travel time corresponds to the 89 percentile of the travel to work, the 91 percentile to study, the 94 percentile to shop, the 90 percentile to leisure travel, and the 91 percentile to social travel. So, a threshold based on the total trips hides inequities in different travel purposes. This study used different thresholds by trip purpose, with the statistical criterion of the 90 percentile (to identify $10 \%$ of longer trips).

Thus, we found 1,071,253 (in the week) inequitable trips, from a total of 14,515,272 trips of the Metropolitan Area of Barcelona (7.38\%). 54.9\% of these journeys are from the low class, $27.0 \%$ from the middle class, and $18.1 \%$ from the high class. The purpose distribution is as follows: $40.8 \%$ are travel to work, $21.7 \%$ to study, $6.5 \%$ to shop, $4.3 \%$ leisure travel, $6.6 \%$ social travel, and $20.1 \%$ for other purposes. The modal distribution is $18.9 \%$ for walking journeys or bike trips, $20.7 \%$ by car, $17.6 \%$ by bus, $15.7 \%$ by metro, and $26.6 \%$ by train.

In summary, the inequitable journeys are concentrated in the low class (but with a significant percentage in the high class), in travel to work (but all the other purposes together have a greater percentage), and with homogeneous modal distribution. These non-traditional characteristics of inequity show the dimensions that provide the approach of the social use of the city to the inequity in urban transport.

Figure 1 shows the results of the assignment process (flow of inequitable journeys with the thickness of the line), and the specialisation of the transport corridors (arc with red colour). The specialisation index is the ratio between the percentage of inequitable trips in each network arc, and the percentage of inequitable trips in the whole metropolitan area. A value over 1 indicates that the arc has a greater percentage than the city. This situation is understood as specialisation in this inequitable travel (a high value, over 1, indicates high specialisation).

The figure shows that the inequitable travel to work journeys concentrate their specialisation in the structural roads, namely Av. Diagonal and Av. Meridiana, in the direction to the centre of the city (Pl. Cataluña). The inequitable journeys for study purposes concentrate their specialisation in an orbital road system from Barcelona, but not in a direction towards the centre. The inequitable shopping related journeys concentrate their specialisation around the centre of the city (Pl. Cataluña), as do the leisure related trips concentrating their specialisation in the same corridors, but also in the structural roads out of the city. The social related trips concentrate their specialisation in a wider area around the centre (Pl. Cataluña and Gracia).

For a clearer view of this specialisation, Figure 2 shows a profile of Av. Diagonal in the city of Barcelona, in terms of the specialisation index.

In the profile table we can see that the greater specialisation of this corridor is for the purposes of shopping and social activities, between Zona Universitaria and Pl. Francesc Macia (large shopping centres and offices are located in this 
The inequitable travel to work

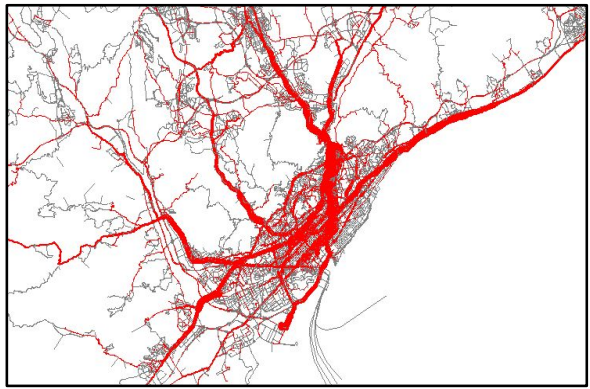

The inequitable travel to shop

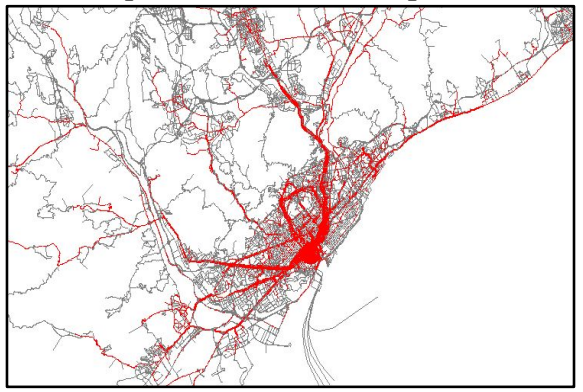

The inequitable travel to study

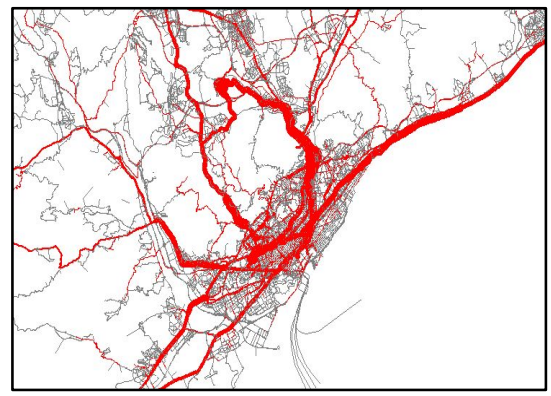

The inequitable leisure trips

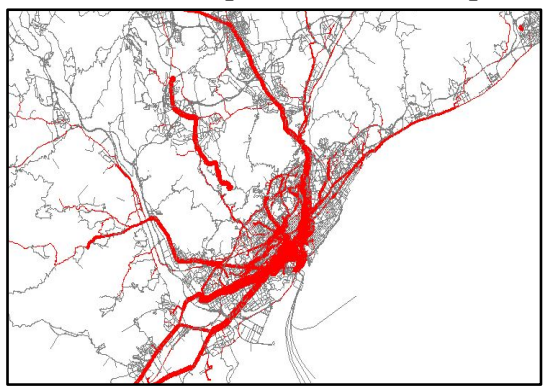

The inequitable social trips

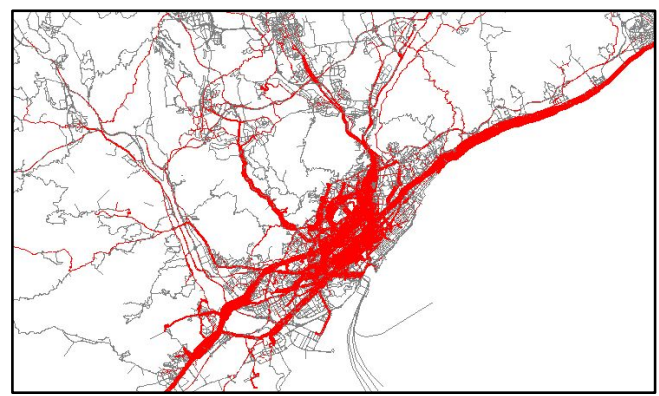

Figure 1: Specialization corridors in inequitable travel time, for different purposes (colour online only).

sector). In the same sector the specialization of the inequitable leisure trips are concentrated. The specialisation in inequitable travel to work and to study, are not significant in this corridor.

In summary, the profile shows the potential social benefits of investment in transport, in terms of reducing inequities in travel times for different purposes of the use of the city. With this approach, the real benefits of transportation projects are evaluated in terms of the trip chain, and not only in specific sections of the network. 


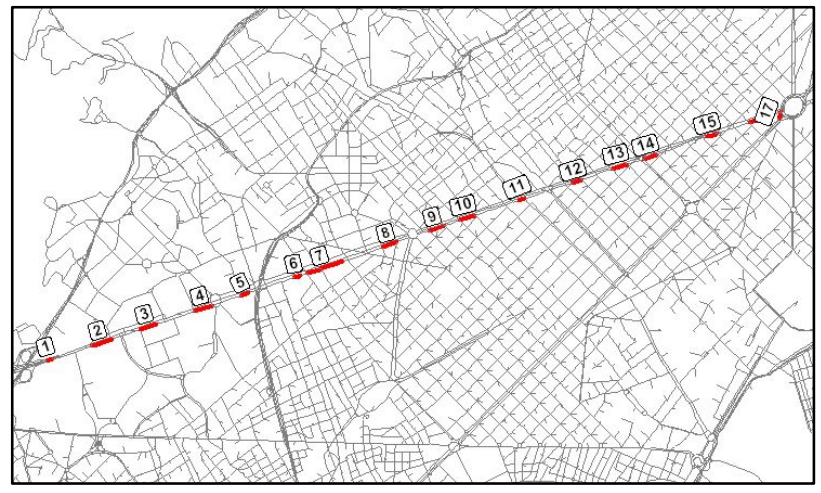

\begin{tabular}{|c|c|c|c|c|c|c|}
\hline \multirow[b]{2}{*}{ Reference } & \multirow[b]{2}{*}{ Point } & \multicolumn{5}{|c|}{\begin{tabular}{|c|} 
Specialization in inequity travel \\
\end{tabular}} \\
\hline & & To work & To study & To shop & Leisure & Social \\
\hline & 1 & 3,0 & 3,8 & \begin{tabular}{|l|}
11,4 \\
\end{tabular} & 1,4 & 11,0 \\
\hline \multirow[t]{3}{*}{ Zona Universitaria } & 2 & 3,1 & 4,5 & 12,0 & 3,1 & 12,2 \\
\hline & 3 & 3,0 & 4,0 & 10,7 & 3,1 & 12,2 \\
\hline & 4 & 2,8 & 3,8 & 10,0 & 3,1 & 12,2 \\
\hline \multirow[t]{3}{*}{ PI. Maria Cristina } & 5 & 2,8 & 4,6 & 9,8 & 3,2 & 12,1 \\
\hline & 6 & 2,8 & 4,5 & 7,4 & 3,2 & 10,7 \\
\hline & 7 & 3,0 & 4,6 & 7,4 & 3,3 & 10,7 \\
\hline \multirow[t]{3}{*}{ PI. Francesc Macia } & 8 & 2,0 & 4,8 & 5,3 & 2,0 & 10,3 \\
\hline & 9 & 1,9 & 4,1 & 4,7 & 1,0 & 12,5 \\
\hline & 10 & 1,8 & 3,8 & 4,1 & 1,1 & 11,1 \\
\hline \multirow[t]{3}{*}{ Psg. Gracia } & 11 & 1,6 & 4,3 & 3,0 & 1,4 & 7,6 \\
\hline & 12 & 1,4 & 4,1 & 4,0 & 1,3 & 5,2 \\
\hline & 13 & 1,4 & 4,2 & 3,5 & 0,8 & 5,2 \\
\hline \multirow[t]{2}{*}{ Psg. Sant Joan } & 14 & 1,4 & 4,2 & 3,3 & 1,0 & 5,2 \\
\hline & 15 & 0,8 & 0,0 & 3,5 & 0,0 & 5,0 \\
\hline PI. Glories & 16 & 0,9 & 0,0 & 3,8 & 0,0 & 3,5 \\
\hline
\end{tabular}

Figure 2: $\quad$ Profile of specialization index across Diagonal Avenue, Barcelona.

\section{Conclusion}

Other studies of travel time traditionally use the average travel time [11], but as shown, the travel time is a random variable of mobility, whose statistical distribution is not usually symmetrical. So, it would be wrong to use the average time as a representative value.

The functional probability shows a "willingness to spend time on travel", in other words it is the probability to make or not the trip, for a specific purpose. Then the variation of probability produced by a reduction of time is not constant as the social value of time.

Journeys with inequitable travel time, identified by a statistical approach, are concentrated in 1) the lower class, but also with a significant percentage in the higher class, 2) in travel to work, but all the other purposes together have a 
greater percentage, and 3) with homogeneous modal distribution. These nontraditional characteristic of inequity show the dimensions that provide the approach of the social use of the city, to the inequity in urban transport.

The Barcelona transport corridors are specialised in space and purpose. The specialisation profile of a specific corridor shows the potential social benefits of investment in transport, in terms of reducing inequities in travel times of different purposes of the use of the city. With this approach, the real benefits of transportation projects are evaluated in terms of the trip chain, and not only in specific sections of the network.

The main conclusion of the research is that by taking a social view of travellers, with regard to their different purposes and social class, in the form of how they use the city in terms of space and time, is a more realistic criterion to prioritise different transport corridors, by carrying out the analysis of who makes use of them, for what reason, and for how long.

\section{Acknowledgements}

The lead author is supported by the "Comisionado para Universidades $e$ Investigación del Departamento de Innovación, Universidades y Empresa de la Generalitat de Cataluña y del Fondo Social Europeo”. The study is supported by the Ministerio de Fomento del Gobierno de España.

\section{References}

[1] Autoritat del Transport Metropolità, Pla Director de Mobilitat, Barcelona, 2007. Online. http://www.atm.cat/cat/apartado3/ap3_04.htm

[2] Banco Interamericano de Desarrollo, Manual de Evaluación Económica de Proyectos de Transporte, Washington D.C., pp. 188, 2006. Online. http://idbdocs.iadb.org/wsdocs/getdocument.aspx?docnum=1037792

[3] Bhat, CR., A retrospective and prospective survey of time-use research. Transportation, 26, pp. 119-139, 1999.

[4] Bhat, CR., Activity-based Travel Demand Analysis: The Past, the Present, and The Future. Presentation of the Time Use Observatory (TUO) Workshop. Santiago, 2009. Online http://www.sistemasdeingenieria.cl/ seminarios/descargas/PresentacionTUO_Final.pdf

[5] Cerda, J. El comportamiento del mercado inmobiliario en la Cuenca operacional del Gran Santiago: un nuevo enfoque de análisis (Chapter 3.2). Producción inmobiliaria y reestructuración metropolitana en América Latina, eds P. Pereira \& R. Hidalgo, Serie GEOLibros - PUC: Santiago, pp. 89-106, 2008.

[6] Hunt, J.D. et al, Current Operacional Urban Land-use-transport Modelling Frameworks: a review. Transport Reviews, 25(3), pp. 329-376, 2005.

[7] Kaufmann, V., Motility: Mobility as Capital. International Journal of Urban and Regional Research, 28(4), pp. 745-756, 2004.

[8] Miller, H., Necessary space-time conditions for human interaction. Environment and Planning B: Planning and Design, 32, pp. 381-401, 2005. 
[9] Miralles, C., Ciudad y transporte un binomio imperfecto, Ariel Geografía: Barcelona, pp. 300, 2002.

[10] Munizaga, M., Correia, R., Jara, S., Ortuzar, J., Valuing time with a join mode choice-activity model. International Journal of Transportation Economics, 33, pp. 69-86, 2006.

[11] Van Wee, B., Rietveld, P. \& Meurs, H., Is average daily travel time expenditure constant? In search of explanations for an increase in average travel time. Journal of Transport Geography, 14, pp. 109-122, 2006. 